\title{
BMJ Are children carrying the burden of open broad-spectrum antibiotics in general practice? Prescription pattern for paediatric outpatients with respiratory tract infections in Norway
}

\author{
Guro Haugen Fossum, ${ }^{1,2}$ Morten Lindbæk, ${ }^{1}$ Svein Gjelstad, ${ }^{1}$ Ingvild Dalen, ${ }^{1}$ \\ Kari J Kværner ${ }^{3,4}$
}

To cite: Fossum GH, Lindbæk M, Gjelstad S, et al. Are children carrying the burden of broad-spectrum antibiotics in general practice? Prescription pattern for paediatric outpatients with respiratory tract infections in Norway. BMJ Open 2013;3: e002285. doi:10.1136/ bmjopen-2012-002285

- Prepublication history and additional material for this paper are available online. To view these files please visit the journal online (http://dx.doi.org/10.1136/ bmjopen-2012-002285).

Received 30 October 2012 Revised 30 October 2012 Accepted 3 December 2012

This final article is available for use under the terms of the Creative Commons Attribution Non-Commercial 2.0 Licence; see http://bmjopen.bmj.com

For numbered affiliations see end of article.

Correspondence to Dr Guro Haugen Fossum; g.h.fossum@medisin.uio.no

\section{ABSTRACT}

Objectives: To investigate the antibiotic prescription pattern and factors that influence the physicians' choice of antibiotic.

Design: Observational study.

Setting: Primary healthcare in Norway, December 2004 through November 2005.

Participants: 426 general practitioners, GPs, in Norway, giving 24888 respiratory tract infection episodes with 19938 children aged 0-6 years.

Outcome measures: Assess antibiotic prescription details and patient and GP characteristics associated with broad-spectrum and narrow-spectrum antibiotic use.

Results: Of the 24888 episodes in the study, $26.2 \%(95 \% \mathrm{Cl} 25.7 \%$ to $26.8 \%$ ) included an antibiotic prescription. Penicillin $\mathrm{V}$ accounted for $42 \%$ and macrolide antibiotics for $30 \%$. The prescription rate varied among the physicians, with a mean of $25.5 \%$ (95\% Cl $24.2 \%$ to $26.7 \%$ ). Acute tonsillitis gave the highest odds for a prescription, OR $33.6(95 \% \mathrm{Cl} 25.7 \%$ to $43.9 \%)$, compared to 'acute respiratory tract infections and symptoms' as a reference group. GPs with a prescription rate of $33.3 \%$ or higher had the larger probability for broad-spectrum antibiotic prescriptions, OR $3.33(95 \% \mathrm{Cl} 2.01 \%$ to $5.54 \%)$. Antibiotic prescriptions increased with increasing patient age.

Conclusions: We found a low antibiotic prescription rate for childhood respiratory tract infections. However, our figures indicate an overuse of macrolide antibiotics and penicillins with extended spectrum, more so than in the corresponding study including the adult population. Palatability of antibiotic suspensions and other administrative challenges affect medication compliance in children. To help combat antibiotic resistance, guidelines need to be followed, in particular for our youngest patients.

Trial registration number (clinicaltrials.org): NCT00272155.

\section{ARTICLE SUMMARY}

Article focus

- Scandinavia has a conservative prescription pattern for antibiotics in respiratory tract infections.

- Norwegian guidelines recommend the use of phenoxymethylpenicillin in almost all upper respiratory tract infection in general practice (GP).

- Specific challenges apply when prescribing drugs to children.

\section{Key messages}

- The general prescription rate for antibiotics in respiratory tract infections is relatively low in Norway, but higher in children than adults.

- Norwegian GPs tend to overprescribe macrolide antibiotics to children.

- The national guidelines for antibiotics in GP are not followed in children diagnosed with bronchitis/bronchiolitis.

Strengths and limitations of this study

- Large data set with representative GPs from different parts of Norway participating.

- Analyses performed at the episode level, limiting the risk of including revisits for the same illness.

- Data mainly from 2005; however, recent data from the Norwegian Prescription Data base indicate that the prescription pattern has undergone few changes since then.

\section{INTRODUCTION}

Almost $90 \%$ of antibiotics sold in Norway are prescribed in the primary healthcare sector. ${ }^{1}$ The most common antibiotic subtype is phenoxymethylpenicillin, followed by erythromycin, pivmecillinam and doxycycline. ${ }^{2}$ Although the Scandinavian prescription pattern is conservative, the European trend of increased use of broad-spectrum penicillins and macrolide 
antibiotics is also found in Norway. ${ }^{2-4}$ Recent figures from both Holland and the USA from 1998 to 2004 confirmed the tendency. ${ }^{5} 6$

The use of antibiotics in Norwegian children aged $0-4$ years was approximately $30 \%$ in $2005 / 2006$, compared to an average of about $24 \%$ in the general population. ${ }^{1}$ Users per 1000 aged $0-9$ years were 220 in 2005 and 227 in 2011. ${ }^{7}$ Most prescriptions for children in primary healthcare are results of common airway infections. A Norwegian study from 1989 found that $80 \%$ of general practice (GP) contacts for children aged 012 years with the diagnoses tonsillitis, sinusitis, acute bronchitis, bronchiolitis and pneumonia were prescribed antibiotics, with phenoxymethylpenicillin as the drug of choice. $^{8}$

When prescription rates are considered, it is important to keep in mind that several studies from GP show that consultations for upper respiratory tract infections (RTIs) are decreasing, while the proportion of antibiotic prescriptions remains constant. ${ }^{9-12}$ Variations in physician seeking behaviour and changing prescription pattern among GPs are suggested explanations. Adequate and rational use of antibiotics is one needed action to prevent and combat antibiotic resistance, ${ }^{13} 14$ hence several surveillance systems monitor the use of antibiotics on national and European levels. ${ }^{15-17}$ The proportion of pneumococcus airway isolates with reduced penicillin sensitivity was $3.3 \%$ in 2007 and shows an increasing tendency. ${ }^{16}$ Erythromycin resistance in pneumococcus airway isolates increased from $2 \%$ in 2000 to $12.4 \%$ in 2006 but decreased to $9.4 \%$ in $2007 .^{16}{ }^{18}$ Resistance to macrolide antibiotics is of particular importance in children. Studies have shown resistant strains in their oral flora in $17 \%$ of patients 6 weeks following treatment with erythromycin, and $85 \%$ for azithromycin. ${ }^{19}$

Norwegian guidelines present phenoxymethylpenicillin as the drug of choice in almost all upper RTIs if antibiotics are required. ${ }^{20}$ The level of resistance is low, and the only reasons for second-choice antibiotics are penicillin allergy or treatment failure. Compliance is an important issue when antibiotic suspensions are subscribed, palatability being one determinant. ${ }^{21}$

The aim of the study was to investigate the prescription pattern of antibiotics for RTIs in Norwegian primary healthcare in preschool children; estimate the prescription rate and assess factors affecting the GP's prescription pattern.

\section{MATERIAL AND METHODS}

The Prescription Peer Academic Detailing (Rx-PAD) Study was initiated in 2004 at the University of Oslo to provide structured training in the use of prescription drugs for GPs. Eighty GP training groups including approximately 450 physicians from different parts of the country were recruited with the purpose of raising awareness and improving GP's prescription patterns in
RTIs and prescription drugs for the elderly. ${ }^{22}$ As part of the Rx-PAD study, a 1-year sampling of baseline data from 441 GPs were performed (December 2004 through November 2005); the material of the present study. All RTI diagnoses were included, based on the International Classification of Primary Care (ICPC-2) coding system. ${ }^{23}$ Data were extracted from the doctors' computer systems using software developed by Mediata AS.

Of the 441 GPs in the project, 12 GPs with less than 10 registered episodes, 72 episodes where patient gender was missing and 3 GPs in rural practices with an over-the-counter delivery of antibiotics were excluded. The total number of episodes available for analysis were 24 888, including 19938 patients and 426GPs (figure 1).

The Rx-PAD database was merged with the Norwegian National Prescription Database (NorPD). Informations included in the database are the drug-specific anatomical therapeutic chemical codes, name, strength, administration form, compound size and the date of withdrawal by the patient. ${ }^{24}$

The outcome of interest for the present study was antibiotic prescription details from the GPs. The following diagnoses were included according to the ICPC-2 classification system: acute RTIs and symptoms (R01-29, 74, 80 ), acute bronchiolitis/bronchitis (R78), pneumonia (R81), acute otitis media and ear pain (H01,71, 72, 74), acute tonsillitis (R72, 76) and other RTIs including sinusitis, laryngitis and asthma (R71, 75, 77, 79, 83, 95, 96). ${ }^{23}$

Consultations with preschool children, aged 0-6 years, were extracted from the Rx-PAD baseline data to form a distinct database in SPSS. Consultations within 30 days of each other were combined to form one episode, of which the first antibiotic prescription of the episode was selected for further analysis. Analyses were performed by episode; one patient may be included more than once. Less common antibiotics were grouped. Antibiotics common for urinary tract infections and rarely in use for respiratory infections (nitrofurantoin, trimethoprim, pivmecillinam and methenamine) were coded as no antibiotic prescription.

Descriptive statistics were estimated in IBM SPSS Statistics V.19. Logistic regression models were used to identify predictors of antibiotic prescription and predictors of broad-spectrum antibiotic prescription in Stata IC/11.2 for Windows. The results from logistic regression analyses were adjusted for clustering by means of multilevel modelling with random intercept at the group and doctor level, and random slope at diagnoses for doctors.

\section{RESULTS}

GP characteristics are shown in table 1 .

A total of 426 GPs were included in the study, $31.5 \%$ and $68.5 \%$ females and males, respectively. A total of $86 \%$ of the physicians were authorised GP specialists. Most GPs worked in a group practice. 
Figure 1 Selection process after data from 441 general practitioners (GPs) and 25093 respiratory tract infection episodes for 1 year (December 2004 through November 2005) were collected.

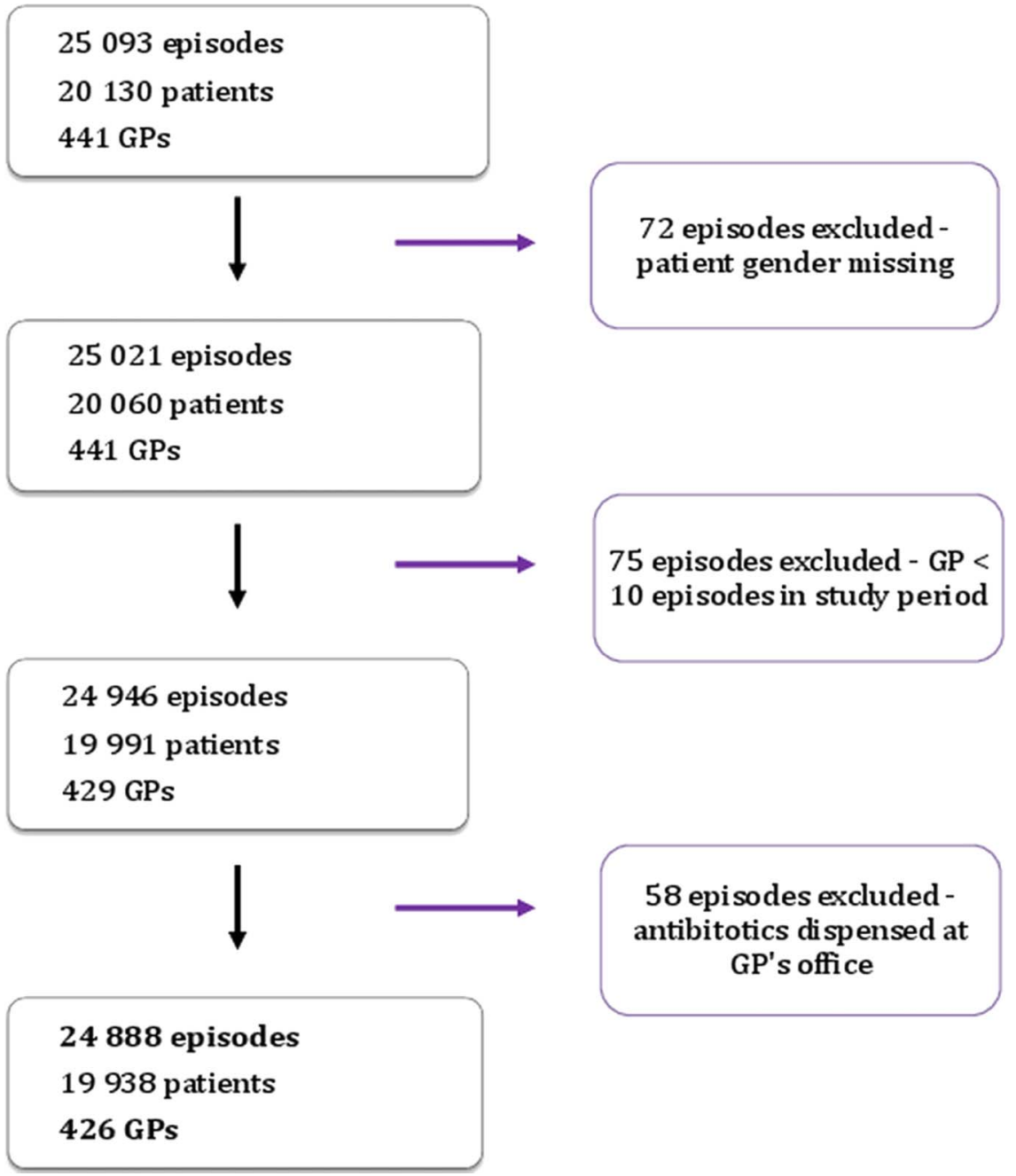

Table 1 Characteristics of 426 participating general practitioners (GPs)

\begin{tabular}{|c|c|c|}
\hline $\begin{array}{l}\text { Characteristic } \\
(\mathrm{n}=426)\end{array}$ & Number & $\%(95 \% \mathrm{Cl})$ \\
\hline \multicolumn{3}{|l|}{ Gender } \\
\hline Female & 135 & 31.7 (27.3 to 36.1 ) \\
\hline Male & 291 & 68.3 (63.9 to 72.7$)$ \\
\hline \multicolumn{3}{|l|}{ Group practice } \\
\hline Yes & 394 & 92.5 (90.0 to 95.0$)$ \\
\hline No & 32 & 7.5 (5.0 to 10.0$)$ \\
\hline \multicolumn{3}{|l|}{ GP specialist } \\
\hline Yes & 365 & 85.7 (82.4 to 89.0 ) \\
\hline No & 61 & 14.3 (11.0 to 17.6$)$ \\
\hline \multicolumn{3}{|l|}{ Practice location } \\
\hline City & 233 & 54.7 (50.0 to 59.4 ) \\
\hline \multirow[t]{2}{*}{ Rural } & 193 & 45.3 (40.6 to 50.0$)$ \\
\hline & Mean & Median (range) \\
\hline Age (years) & 49 & 50 (28 to 67$)$ \\
\hline $\begin{array}{l}\text { Years since } \\
\text { authorisation }\end{array}$ & 19 & $20(0$ to 41$)$ \\
\hline $\begin{array}{l}\text { Number of listed } \\
\text { patients }\end{array}$ & 1328 & 1316 (0 to 3385) \\
\hline Consultations per year & 3095 & 3029 (309 to 11252) \\
\hline
\end{tabular}

The prescription pattern among GPs varied considerably, with a mean of 25.5 (95\% CI 24.2 to 26.7) antibiotic prescriptions per 100 episodes. For broad-spectrum antibiotic proportion, the corresponding figure was 53.7 (95\% CI 50.7 to 56.7). Among the latter, more than 50 doctors prescribed broad-spectrum antibiotics every time (figure 2).

Respiratory infections were most common among 2-year-olds to 3-year-olds, $41 \%$ experienced infections and fewer episodes were found in June, July and August. Of the 24888 episodes, $53 \%$ were boys and $47 \%$ were girls. The three most common diagnoses were acute upper RTI (R74), cough (R05) and acute otitis media (H71), 27\%, $18 \%$ and $16 \%$, respectively. A total of $20 \%$ of the episodes are repeating visits.

An antibiotic prescription was registered in $26.2 \%$ (6525) of all episodes. Penicillin V was prescribed most frequently, followed by macrolide/lincosamide antibiotics. In the latter group, lincosamides accounted for only $1.3 \%$; the group is therefore referred to as macrolides. ${ }^{25}$ Few registered prescriptions of tetracyclines and cephalosporins for RTIs were found. Episodes with acute tonsillitis resulted in a prescription in $77 \%$, and more than 


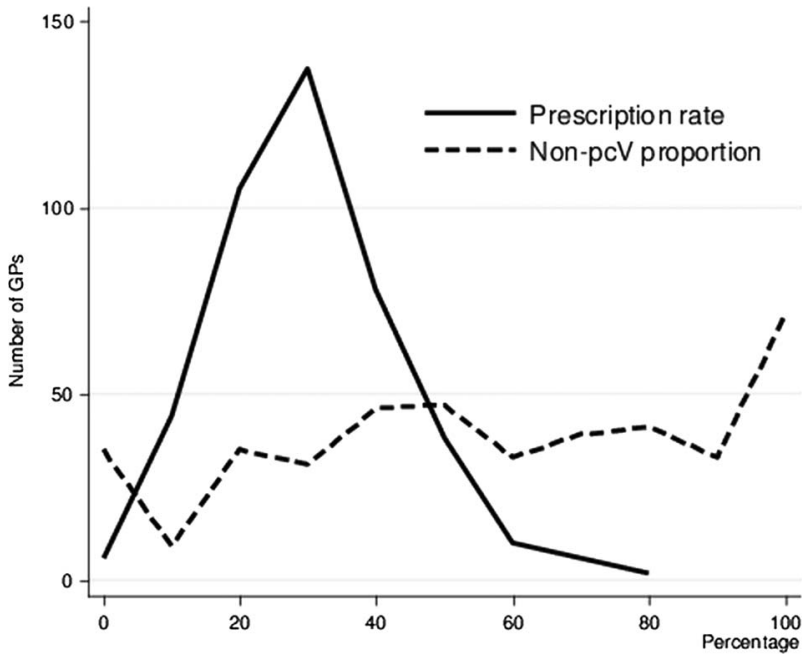

Figure 2 Antibiotic prescription rates for respiratory tract infection episodes and proportion broad-spectrum antibiotic prescriptions among the 426 participating general practitioners.

$67 \%$ of the prescriptions were penicillin V. As shown in table 2, a high antibiotic rate for acute bronchitis was found, $40 \%$, with macrolide antibiotics as the choice of preference. When patients were diagnosed 'other RTIs', only $12 \%$ of the episodes resulted in antibiotic prescriptions. In the latter, $52 \%$ of the episodes resulted in macrolide antibiotics and $22 \%$ in penicillins with extended spectrum. In the otitis media group where antibiotics were prescribed, penicillin $\mathrm{V}$ and penicillins with extended spectrum were provided in $46 \%$ and $33 \%$, respectively. A lower prescription rate was found in children below age $1(n=1552)$, where only $10 \%$ received an antibiotic prescription.

Predictors for antibiotic prescriptions are shown in table 3. Tonsillitis and pneumonia gave the highest OR for antibiotics among the diagnostic groups, with ORs of 33.6 (95\% CI 25.7 to 43.9 ) and 16.5 (95\% CI 12.7 to 21.4), respectively. Older children had an increased probability for antibiotics compared to the age group $0-1$ years (table 3$)$. Gender or GP characteristics did not predict antibiotic prescriptions, except for GPs with a high work load (measured by annual consultations), which were more frequent prescribers. Bivariate analysis found increased ORs for antibiotic prescriptions among GPs in single practice and non-specialists, but these differences did not remain significant after adjustment.

Regression analysis on predictors for broad-spectrum antibiotics showed a similar pattern (table 4). The diagnoses giving the highest ORs were the group of other respiratory infections and bronchitis, ORs of 3.04 (95\% CI 2.28 to 4.05 ) and 2.71 (95\% CI 1.91 to 3.86), respectively gave the highest ORs compared to the reference group of acute RTIs. The probability for broad-spectrum antibiotics was low for tonsillitis, and increasing age lowered the probability (table 4). Predictors of broadspectrum antibiotics with regard to the GP gave higher ORs for specialist GPs. The most significantly increased OR was seen in high prescribers, OR 3.33 (95\% CI 2.01 to 5.54 ), for GPs with prescription rates of $33.3-77.8 \%$.

\section{DISCUSSION}

Our results showed frequent use of broad-spectrum antibiotics for RTIs in children, but a low overall

Table 2 Antibiotic prescriptions of 426 GPs for 24888 RTI episodes for 1 year (December 2004 through November 2005) according to ICPC-2 diagnoses and type of antibiotic

\begin{tabular}{|c|c|c|c|c|c|c|c|}
\hline Diagnoses & $\begin{array}{l}\text { ICPC-2 } \\
\text { codes }\end{array}$ & $\begin{array}{l}\text { Episodes } \\
\mathbf{N}\end{array}$ & $\begin{array}{l}\text { Prescription rate } \\
(\%)(95 \% \mathrm{Cl})\end{array}$ & PcV n (\%) & Pc-Ext n (\%) & Mac n (\%) & Other J01 n (\%) \\
\hline $\begin{array}{l}\text { Acute upper } \\
\text { respiratory tract } \\
\text { infections and } \\
\text { symptoms }\end{array}$ & $\begin{array}{l}\text { R01-29, } \\
74,80\end{array}$ & 6806 & 13.5 (12.7 to 14.3$)$ & $388(42)$ & $245(27)$ & $272(30)$ & $17(2)$ \\
\hline $\begin{array}{l}\text { Other respiratory } \\
\text { tract infections } \\
\text { (including } \\
\text { sinusitis and } \\
\text { laryngitis) }\end{array}$ & $\begin{array}{l}\mathrm{R} 71,75 \\
77,79 \\
83,95\end{array}$ & 8758 & $12.4(11.7$ to 13.1$)$ & $271(25)$ & $236(22)$ & $562(52)$ & $17(2)$ \\
\hline $\begin{array}{l}\text { Acute } \\
\text { bronchiolitis/ } \\
\text { bronchitis }\end{array}$ & $\mathrm{R} 78$ & 1481 & 40.2 (37.7 to 42.7 ) & $141(24)$ & $138(23)$ & $309(52)$ & $8(1)$ \\
\hline Pneumonia & $\mathrm{R} 81$ & 606 & $67.0(63.3$ to 70.7$)$ & $127(31)$ & $97(24)$ & $178(44)$ & $4(1)$ \\
\hline $\begin{array}{l}\text { Acute otitis and } \\
\text { ear pain }\end{array}$ & $\begin{array}{l}\mathrm{H} 01,71 \\
72,74\end{array}$ & 5961 & 42.5 (41.2 to 43.8$)$ & $1174(46)$ & $832(33)$ & 477 (19) & $53(2)$ \\
\hline Acute tonsillitis & $\mathrm{R} 72,76$ & 1276 & 76.7 (74.4 to 79.0$)$ & $654(67)$ & $137(14)$ & $176(18)$ & $12(1)$ \\
\hline Total & & 24888 & 26.2 (25.7 to 26.7$)$ & $2755(42)$ & $1685(26)$ & $1974(30)$ & $111(2)$ \\
\hline
\end{tabular}


Table 3 Multiple logistic regression analysis showing factors independently associated with 426 general practitioners' (GPs) antibiotic prescriptions for 24888 respiratory tract infection episodes during 1 year (December 2004 through November 2005)

\section{n (episodes)}

Patient factors
Patient's gender
Male (ref)
Female

Group of diagnoses

Acute upper respiratory tract infections and symptoms (ref)

Other respiratory tract infections

Acute bronchitis

Pneumonia

Acute otitis and ear pain

Acute tonsillitis

Patient age

$<2$ years (ref)

$3-4$ years

$5-6$ years

\section{Doctor factors}

Doctor's gender

Male (ref)

Female

16281

Practice location

City (ref)

Rural

14009

10879

23207

Group (ref)

Single

Educational level

GP specialist (ref)

Not specialist

21798

Doctor's age

28-43 (ref)

44-49

55-67

Patient contacts per year

309-2302 (ref)

2303-3028

3029-3711

3712-11252
8607

1681

3090

7096

7544

5833

4415

Adjusted OR (95\% Cl)

1

0.97 (0.90 to 1.04$)$

1

0.76 (0.67 to 0.87$)$

4.35 (3.53 to 5.35 )

16.5 (12.7 to 21.4 )

5.16 (4.55 to 5.85 )

33.6 (25.7 to 43.9 )

1

1.34 (1.24 to 1.46$)$

1.41 (1.28 to 1.54$)$

1

1.06 (0.88 to 1.28$)$

$1.00(0.84$ to 1.18$)$

1

$1.10(0.81$ to 1.49$)$

1

1.38 (1.06 to 1.81$)$

1

$1.19(0.94$ to 1.52$)$

1.05 (0.82 to 1.36$)$

1.12 (0.86 to 1.44$)$

4025

5495

$1.16(0.91$ to 1.47$)$

7060

1.27 (0.99 to 1.62$)$

1.54 (1.20 to 1.97$)$

Significant values in bold, $p<0.05$.

prescription rate. Overprescription was found for bronchitis and in busy GPs.

Although penicillin $\mathrm{V}$ was the most frequent preferred choice of antibiotic in $42 \%$ of childhood diagnoses, a high percentage of broader spectrum antibiotics, especially macrolides, was found. An overall $30 \%$ macrolide use is seen in the present study. A proportion of 52\% for bronchitis differs from a bronchitis macrolide proportion of $32 \%$ in the corresponding study where adult data also are included. ${ }^{26}$ The use of penicillin with extended spectrum is recommended prior to the use of macrolides due to resistance issues. ${ }^{16} 1819$ Macrolides, according to the Norwegian guidelines for antibiotic use in primary care, ${ }^{20} 27$ are first choice of preference only in suspected atypical pneumonia or penicillin allergy. In our study they have been used for other diagnoses as well. One explanation may, at least in part, be administrative convenience and a more preferential taste compared to the bitter-tasting penicillin V. It has been found that tolerability, taste and administrative frequency are of importance in paediatric populations. ${ }^{21} 2829$ When Hoppe and co-workers tested paediatric compliance in oral antibiotics, a compliance of $94 \%$ and $90 \%$ was found for clarithromycin and erythromycin. Correspondingly, penicillin V suspensions had a compliance rate of $62 \%$ and $56 \%{ }^{30}$ Hinnerskov et a $\hat{l}^{31}$ have highlighted a similar problem of macrolide overuse in Denmark. 
Table 4 Multiple logistic regression analysis showing factors independently associated with 426 general practitioners' (GPs) proportion of broad-spectrum antibiotics (non-penicillin V) for 6525 respiratory tract infection episodes with prescribed antibiotic for 1 year (December 2004 through November 2005)

n (episodes)

Adjusted OR $(95 \% \mathrm{Cl})$

Patient factors
Patient's gender
Male (ref)
Female

Group of diagnoses

Acute upper respiratory tract infections and symptoms (ref) 922

Other respiratory tract infections

Acute bronchitis 596

Pneumonia 406

Acute otitis and ear pain $\quad 2536$

Acute tonsillitis $\quad 979$

Patient age

$<2$ years (ref)

1533

$3-4$ years

2888

$5-6$ years

2104

$1.04(0.91$ to 1.19$)$

Doctor factors

Doctor's gender

Male (ref)

4310

3.04 (2.28 to 4.05 )

2.71 (1.91 to 3.86 )

2.10 (1.46 to 3.02 )

1.11 (0.87 to 1.43$)$

0.24 (0.18 to 0.33 )

Female

2215

Practice location

City (ref)

3689

Rural

2836

1.13 (0.94 to 1.35$)$

0.79 (0.66 to 0.96$)$

Practice type

Group (ref)

6038

Single

487

1.21 (0.61 to 2.34 )

ducational leve

GP specialist (ref)

5658

1

Not specialist

0.53 (0.30 to 0.94$)$

Doctor's age

28-43 (ref)

1878

44-49 -1927

1

$50-54 \quad 1489$

$0.71(0.43$ to 1.19$)$

$1.06(0.62$ to 1.80$)$

$55-67$

1231

0.85 (0.49 to 1.49$)$

Patient contacts per year

309-2302 (ref)

955

1367

1

2303-3028

1889

$1.48(0.90$ to 2.44$)$

3029-3711

$1.23(0.74$ to 2.06$)$

3712-11252

2314

1.44 (0.85 to 2.46$)$

Antibiotic prescription rate (\%)

0-15.60 (ref)

580

1236

1

15.61-23.64

1942

23.65-33.33

2767

1.15 (0.69 to 1.90$)$

1.37 (0.84 to 2.23$)$

3.33 (2.01 to 5.54 )

Significant values in bold, $\mathrm{p}<0.05$.

The overall prescription rate of only $26 \%$ for RTIs in children aged $0-6$ years in our study was rather low compared to the corresponding data including the adult population. ${ }^{26}$ Although a low rate in preschool children of $24 \%$ was found of the latter, a high proportion was broad-spectrum antibiotics. ${ }^{26}$ Blix $e t a l^{1}$ reported population prevalence for all antibiotic prescriptions of $24 \%$ and for children $0-4$ years about $30 \%$ in 2005/2006. Our selection only included RTIs, and is, accordingly, somewhat lower. Compared to a Norwegian study from $1998,{ }^{8}$ a prescription rate of only $26 \%$ shows a decreasing tendency. In 1998, antibiotics were the rule rather than the exception for children visiting GPs for otitis media, tonsillitis, sinusitis, bronchitis/bronchiolitis and pneumonia. ${ }^{8}$

Antibiotic prescriptions by diagnosis showed a similar distribution pattern to that of the corresponding dataset including adults, but a higher rate for otitis media and a lower rate for symptom diagnoses and bronchitis. ${ }^{26}$ Substantial effort has been performed in Norway the past decade to decrease the prescription rate of antibiotics. 
Our data indicate that these efforts are about to pay off. For instance, we found a low antibiotic prescription rate in patients with otitis media, $42.5 \%$. This is in accordance with current Norwegian guidelines. ${ }^{20}$ Comparable figures from previous studies on antibiotic prescriptions for RTIs in children in several countries revealed an average prescription rate of $47 \%$. Among the 14 study populations included in the study, Italy and Canada have high levels of 42 and $57 \%$, respectively. Holland and UK have correspondingly low levels of $14 \%$ and $21 \% .^{32}$

\section{Predictors of antibiotic prescriptions}

The prescription rate of $40 \%$ for bronchitis/bronchiolitis was worryingly high. This figure is lower than the former study from $1998,{ }^{8}$ but not in correspondence with current Norwegian guidelines. ${ }^{20}$ Considerable improvement in prescription routines is needed. Cochrane reviews have shown no evidence for treating acute bronchiolitis in children with antibiotics, and only a modest beneficial effect when treating patients $8-65 .^{33}$ No obvious explanation to the high prescription rate for bronchitis is evident, but one reason may be a perceived patient or parental demand for prescription, as reported by Little et al..$^{35}$ We also suspect that some diagnoses may be registered based on symptom findings, although the GP suspected more serious illness and subsequently prescribed antibiotics. $\mathrm{C}$ reactive protein (CRP), CRP-testing, is usually performed following clinical examination, and after the ICPC-2 coding. Elevated CRP may cause a prescription without a corresponding change in the initial ICPC-2 code. In the present study, 12-14\% received antibiotics based on symptom diagnoses only. Jansen et al report similar results from Holland, with a symptom diagnose prescription rate of $12-15 \%$ for preschool children. ${ }^{36}$ Such infections are likely to have viral pathology. A correspondingly low prescription rate is expected.

Children aged 5-6 years had the highest probability for antibiotic prescriptions, children below age 2 the lowest. An opposite pattern was seen in the prescription pattern for broad-spectrum antibiotics. Another factor influencing antibiotic prescription was related to GP experience, as GP non-specialists were more likely to prescribe antibiotics. A high number of patient contacts per year increased prescription likelihood. High antibiotic prescription rates increased the probability for broad-spectrum antibiotics. Slightly surprising, GP specialists tend to use more broad-spectrum antibiotics than those without the specialist authorisation. Similar results are presented by Clavenna et al, suggesting that physician attitude may play a role obtaining prudent antibiotic prescriptions ${ }^{37}$. Antibiotic overuse may also be affected by an existing gap between perceived and real determinants of antibiotic prescription. ${ }^{38}$

\section{Strengths and limitations}

The major strength of this study is the large number of infectious episodes in the data set. The study period comprised a complete year, including all seasonal variations. GPs from most parts of the Southern Norway participated; urban as well as rural areas. We believe it is likely that our data represent the prescription pattern for RTIs well and that our findings are generalisable to Norwegian GPs. We have chosen to analyse by infectious episodes, with a cut-off at 30 days, well aware that a few new episodes may represent revisits due to treatment failure and follow-up visits by the same patient. Previous studies have been performed based on consultations and by infectious episodes. ${ }^{32} 36$ The consultations in the present study only represent GPs' regular office work, no out-of-hour emergency visits are included. In most of Norway, the same office GPs also are on duty taking care of emergency cases during evenings and nights. A study by Fagan ${ }^{39}$ showed that Norwegian GPs' prescription patterns are identical when regular office consultations are compared to emergency visits for otitis media and tonsillitis. Our data are mainly from 2005; however, figures from NorPD indicate similar patterns of antibiotic use now in $2011 .^{7}$

In conclusion, a low antibiotic prescription rate for childhood RTIs was found. However, the GPs tend to choose macrolide antibiotics and penicillins with extended spectrum more often than the guidelines recommend. We recognise the specific challenges that are related to medication compliance in children. Administrative simplifications, such as the availability to oral penicillin suspensions during meals, may help shift the trend away from broad-spectrum antibiotics. ${ }^{40}$ Palatability may also affect compliance, taking penicillin V's bitter taste into account. Differences between GPs can be targeted by more individual and specified means. We recommend that GPs replace narrow spectered penicillins with extended spectered penicillins rather than macrolides as second-choice antibiotic in RTIs.

\section{Author affiliations}

${ }^{1}$ Department of General Practice, Institute of Health and Society, University of Oslo, Oslo, Norway

${ }^{2}$ Division of Surgery and Clinical Neuroscience, Department for Otorhinolaryngology, Head and Neck Surgery, Oslo University Hospital, Oslo, Norway

${ }^{3}$ Research, Innovation and Education Unit, Oslo University Hospital, Oslo, Norway

${ }^{4}$ Department of Health Management and Health Economics, University of Oslo, Oslo, Norway

Contributors GHF, ML and SG conceived the idea of the study and were responsible for the design of the study. GHF, SG and ID were responsible for the data analyses and produced the tables and graphs. ID designed the model used for multilevel analysis. All authors provided input into the data analysis and to the interpretation of the results. The initial draft of the manuscript was prepared by GHF, ML and KJK and then circulated repeatedly among all authors for critical revision.

Funding The Rx-PAD study was carried out with grants from the Norwegian Ministry of Health and the Norwegian Medical Association. The present study is funded as part of a PhD-project by the Antibiotic Center for Primary Care.

Competing interests ICMEJ forms are submitted for all authors. SG is working part time and has ownership in the company that produced software for data extraction in this study. Other authors none to declare. 
Ethics approval The Rx-PAD-study, merged with the data from NorPD was approved by the regional ethics committee, the Norwegian data inspectorate and the Norwegian Directorate of Health.

Provenance and peer review Not commissioned; externally peer reviewed.

Data sharing statement There are no additional data available.

\section{REFERENCES}

1. Blix HS, Engeland A, Litleskare I, et al. Age- and gender-specific antibacterial prescribing in Norway. J Antimicrob Chemother 2007;59:971-6.

2. Litleskare I, Blix HS, Ronning M. Antibiotic use in Norway. Tidsskr Nor Laegeforen 2008;128:2324-9.

3. Goossens H, Ferech M, Coenen S, et al. Comparison of outpatient systemic antibacterial use in 2004 in the United States and 27 European countries. Clin Infect Dis 2007;44:1091-5.

4. Goossens H, Ferech M, Vander Stichele R, et al. Outpatient antibiotic use in Europe and association with resistance: a cross-national database study. Lancet 2005;365:579-87.

5. Coco AS, Horst MA, Gambler AS. Trends in broad-spectrum antibiotic prescribing for children with acute otitis media in the United States, 1998-2004. BMC Pediatr 2009;9:41.

6. de Jong J, van den Berg PB, de Vries TW, et al. Antibiotic drug use of children in the Netherlands from 1999 till 2005. Eur J Clin Pharmacol 2008;64:913-19.

7. Nasjonalt reseptbasert legemiddelregister (the Norwegian Prescription Database). www.reseptregisteret.no (accessed date Oct 2012).

8. Straand J, Rokstad K, Heggedal U. Drug prescribing for children in general practice. A report from the More \& Romsdal Prescription Study. Acta Paediatr 1998;87:218-24.

9. Ashworth M, Charlton J, Ballard K, et al. Variations in antibiotic prescribing and consultation rates for acute respiratory infection in UK general practices 1995-2000. Br J Gen Pract 2005;55:603-8.

10. Kuyvenhoven M, van Essen G, Schellevis F, et al. Management of upper respiratory tract infections in Dutch general practice; antibiotic prescribing rates and incidences in 1987 and 2001. Fam Pract 2006;23:175-9.

11. McCaig LF, Besser RE, Hughes JM. Trends in antimicrobial prescribing rates for children and adolescents. JAMA 2002;287:3096-102.

12. Neumark T, Brudin L, Engstrom S, et al. Trends in number of consultations and antibiotic prescriptions for respiratory tract infections between 1999 and 2005 in primary healthcare in Kalmar County, Southern Sweden. Scand J Prim Health Care 2009;27:18-24.

13. Hoiby EA, Vestrheim DF, Caugant DA, et al. Bacterial resistance against antibiotics. Tidsskr Nor Laegeforen 2008;128:2452-6.

14. Costelloe C, Metcalfe C, Lovering A, et al. Effect of antibiotic prescribing in primary care on antimicrobial resistance in individual patients: systematic review and meta-analysis. BMJ 2010;340: c2096.

15. Coenen S, Ferech M, Malhotra-Kumar S, et al. European Surveillance of Antimicrobial Consumption (ESAC): outpatient macrolide, lincosamide and streptogramin (MLS) use in Europe. $J$ Antimicrob Chemother 2006;58:418-22.

16. Simonsen GS. NORM/NORM-VET 2007. Usage of Antimicrobia Agents and Occurence of Antimicrobial Resistance in Norway. Tromsø/Oslo2008.

17. Statens institutt for folkehelse. Seksjon for forebyggende infeksjonsmedisin. MSIS-rapport/Meldesystemet for smittsomme sykdommer. Oslo: Folkehelsa.

18. Simonsen GS. Surveillance and prevalence of antimicrobial resistance in Norway. Tidsskr Nor Laegeforen 2009;129:623-7.
19. Kastner U, Guggenbichler JP. Influence of macrolide antibiotics on promotion of resistance in the oral flora of children. Infection 2001;29:251-6.

20. Lindbæk M. Helsedirektoratet, Antibiotikasenteret for primærmedisin Nasjonale faglige retningslinjer for antibiotikabruk $i$ primærhelsetjenesten. Oslo: Helsedirektoratet: Antibiotikasenteret for primærmedin, 2008

21. Steele RW, Thomas MP, Begue RE. Compliance issues related to the selection of antibiotic suspensions for children. Pediatr Infect Dis J 2001;20:1-5.

22. Gjelstad S, Fetveit A, Straand J, et al. Can antibiotic prescriptions in respiratory tract infections be improved? A cluster-randomized educational intervention in general practice-the Prescription Peer Academic Detailing (Rx-PAD) Study (NCT00272155). BMC Health Serv Res 2006;6:75.

23. KITH AS, Sosial- og helsedirektoratet, Norsk selskap for allmennmedisin, et al. ICPC-2: den internasjonale klassifikasjonen for primærhelsetjenesten. Norsk utg., 2. utg. ed. (Oslo): Sosial- og helsedirektoratet; 2004.

24. Lindbaek M. What does influence the prescription of antibiotics to children?. Tidsskr Nor Laegeforen 2004;124:2228.

25. Leclercq R, Courvalin P. Bacterial resistance to macrolide, lincosamide, and streptogramin antibiotics by target modification. Antimicrob Agents Chemother 1991;35:1267-72.

26. Gjelstad S, Straand J, Dalen I, et al. Do general practitioners consultation rates influence their prescribing patterns of antibiotics for acute respiratory tract infections? J Antimicrob Chemother 2011;66:2425-33.

27. Berild D, Lindbaek M. Are too many antibiotics prescribed to Norwegian children? Tidsskr Nor Laegeforen 2002;122:2690.

28. Block SL, Schmier JK, Notario GF, et al. Efficacy, tolerability, and parent reported outcomes for cefdinir vs. high-dose amoxicillin/ clavulanate oral suspension for acute otitis media in young children. Curr Med Res Opin 2006;22:1839-47.

29. Ramgoolam A, Steele R. Formulations of antibiotics for children in primary care: effects on compliance and efficacy. Paediatr Drugs 2002;4:323-33.

30. Hoppe JE, Blumenstock G, Grotz W, et al. Compliance of German pediatric patients with oral antibiotic therapy: results of a nationwide survey. Pediatr Infect Dis J 1999;18:1085-91.

31. Hinnerskov M, Therkildsen JM, Cordoba G, et al. Macrolide overuse for treatment of respiratory tract infections in general practice. Dan Med Bull 2011;58:A4356.

32. Rossignoli A, Clavenna A, Bonati M. Antibiotic prescription and prevalence rate in the outpatient paediatric population: analysis of surveys published during 2000-2005. Eur J Clin Pharmacol 2007;63:1099-106

33. Smucny J, Fahey T, Becker L, et al. Antibiotics for acute bronchitis. Cochrane Database Syst Rev 2004;18:CD000245.

34. Spurling GK, Fonseka K, Doust J, et al. Antibiotics for bronchiolitis in children. Cochrane Database Syst Rev 2007;24:CD005189.

35. Little P, Dorward M, Warner G, et al. Importance of patient pressure and perceived pressure and perceived medical need for investigations, referral, and prescribing in primary care: nested observational study. BMJ 2004;328:444.

36. Jansen AG, Sanders EA, Schilder AG, et al. Primary care management of respiratory tract infections in Dutch preschool children. Scand J Prim Health Care 2006;24:231-6.

37. Clavenna A, Bonati M. Differences in antibiotic prescribing in paediatric outpatients. Arch Dis Child 2011;96:590-5

38. Moro M, Marchi M, Gagliotti C, et al. Why do paediatricians prescribe antibiotics? Results of an Italian regional project. BMC Pediatrics 2009;9:69.

39. Fagan M. Is otitis and tonsillitis handled in the same way within normal working hours and out-of-hours?. Tidsskr Nor Laegeforen 2008;128:2340-2.

40. Westin AA, Walstad RA, Spigset $O$. Should penicillin be given on an empty stomach?. Tidsskr Nor Laegeforen 2009;129:2610-12. 